\title{
Assessing the relevance of neighbourhood characteristics to the household food security of low-income Toronto families
}

\author{
Sharon I Kirkpatrick ${ }^{1, *}$ and Valerie Tarasuk ${ }^{2}$ \\ ${ }^{1}$ Division of Cancer Control and Population Sciences, National Cancer Institute, 6130 Executive Boulevard EPN \\ 4005, Bethesda, MD 20892, USA: ${ }^{2}$ Department of Nutritional Sciences, Faculty of Medicine, University of \\ Toronto, Toronto, Canada
}

Submitted 11 May 2009: Accepted 20 January 2010: First published online 3 March 2010

\begin{abstract}
Objective: Although the sociodemographic characteristics of food-insecure households have been well documented, there has been little examination of neighbourhood characteristics in relation to this problem. In the present study we examined the association between household food security and neighbourhood features including geographic food access and perceived neighbourhood social capital.

Design: Cross-sectional survey and mapping of discount supermarkets and community food programmes.

Setting: Twelve high-poverty neighbourhoods in Toronto, Ontario, Canada.

Subjects: Respondents from 484 low-income families who had children and who lived in rental accommodations.

Results: Food insecurity was pervasive, affecting two-thirds of families with about a quarter categorized as severely food insecure, indicative of food deprivation. Food insecurity was associated with household factors including income and income source. However, food security did not appear to be mitigated by proximity to food retail or community food programmes, and high rates of food insecurity were observed in neighbourhoods with good geographic food access. While low perceived neighbourhood social capital was associated with higher odds of food insecurity, this effect did not persist once we accounted for household sociodemographic factors.

Conclusions: Our findings raise questions about the extent to which neighbourhood-level interventions to improve factors such as food access or social cohesion can mitigate problems of food insecurity that are rooted in resource constraints. In contrast, the results reinforce the importance of household-level characteristics and highlight the need for interventions to address the financial constraints that underlie problems of food insecurity.
\end{abstract}

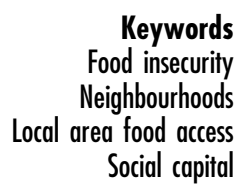

Keywords

Food insecurity rea food access Social capital
Food insecurity - inadequate or insecure access to food in the context of financial constraints - is recognized as a serious public health problem in many affluent countries $^{(1-5)}$. In Canada, an estimated $1 \cdot 1$ million households $(9 \cdot 2 \%)$ were food insecure in $2004^{(1)}$. Although the sociodemographic characteristics of food-insecure households have been well documented through analyses of population health survey data ${ }^{(1,6-8)}$, there has been little examination of neighbourhood characteristics in relation to this problem. However, the existing literature points to two routes through which neighbourhood might influence vulnerability to food insecurity: (i) the local area food environment; and (ii) neighbourhood social capital.

The neighbourhood that one occupies confers advantages and disadvantages of location, including features of the local area food environment. Disparities in food access in relation to socio-economic indicators, as well as deprived areas with poor access to healthy affordable food (often referred to as 'food deserts'), have been documented in both the USA and the $\mathrm{UK}^{(9-12)}$. Interestingly though, research in the UK also suggests that food retail access varies considerably between low-income neighbourhoods, with some neighbourhoods having ample retail outlets ${ }^{(13)}$. This observation is borne out in the findings of existing Canadian research ${ }^{(14-18)}$. For example, a recent study conducted in Montréal examined access to supermarkets in relation to neighbourhood social deprivation and found little evidence of food deserts $^{(14)}$. The authors of a study conducted in London, Ontario, however, concluded that low-income areas in inner-city neighbourhoods have the poorest access to 
supermarkets by walking, although there was good access by public transportation ${ }^{(15)}$. These studies did not assess the association between contextual features of neighbourhoods and household-level food purchasing or consumption.

US research has documented associations between fruit and vegetable consumption and objective measures of supermarket access ${ }^{(19-21)}$. Subjective assessments of the local food environment may also be pertinent, with a recent Australian study showing associations between perceptions of local food availability, accessibility and affordability and frequency of fruit, vegetable and fast-food consumption among women ${ }^{(22)}$. However, studies conducted in Australia and Europe have raised debate about the extent to which food retail access affects food purchasing and consumption once household socio-economic status is taken into account $^{(23-25)}$, and it is not known whether convenient access to food retail can offset problems of food insecurity rooted in resource constraints.

Further, in many Canadian communities, there is now a myriad of local programmes to help offset problems of household food security. These include charitable food assistance programmes (e.g. 'food banks'), community kitchens and community gardens ${ }^{(26-28)}$. Although such initiatives tend to be located in low-income neighbourhoods and may be indicative of the level of povertyrelated services available to residents, the relevance of proximity to these programmes to household food security status is not known.

In addition to access to amenities, it has been postulated that neighbourhood social capital, referring to perceptions of social cohesion and trust in one's community, may be predictive of household food security status ${ }^{(29,30)}$. The observed associations between perceived neighbourhood social capital and indicators of food insecurity in US studies of low-income households ${ }^{(29,30)}$ are consistent with research highlighting the social isolation that characterizes experiences of food insecurity ${ }^{(31-33)}$. While social capital has been linked to health more broadly in other studies ${ }^{(34,35)}$, it has also been postulated that socioeconomic factors are of greater relevance to health ${ }^{36,37)}$ and that low social capital may be an outcome of macrolevel conditions that also lead to poor health rather than being a pathway to poor health ${ }^{(38)}$. Further research is needed to determine the relevance of social capital to food security.

We undertook a study of low-income families in Toronto, Canada, employing survey methods, mapping of neighbourhood food access and in-depth qualitative interviewing, to gain an understanding of factors associated with household food security. We have previously reported rates of food insecurity and participation in community programmes among this sample ${ }^{(39)}$. The objectives of the current paper are to examine the association between household food security and (i) geographic access to food retail and food programmes and (ii) perceived neighbour- hood social capital, drawing upon the survey and neighbourhood mapping data. Given the high levels of deprivation in the sample, we examine neighbourhood characteristics in relation to measures of food insecurity and also severe food insecurity.

\section{Methods}

\section{Sampling and data collection}

Data were collected between November 2005 and January 2007. The study protocol was approved by the Human Subjects Research Ethics Board at the University of Toronto. Families with children and who were tenants were studied because of the association between these household characteristics and vulnerability to problems of food insecurity ${ }^{(1)}$. Families were recruited from twelve high-poverty neighbourhoods (census tracts) randomly selected from twenty-three where more than $40 \%$ of families had low incomes according to the 2001 Census $^{(40)}$. The sample was stratified to include families living in market and subsidized rental units and potential respondents in each census tract were approached at the door by trained interviewers with personal experience of low income.

Respondents were eligible for inclusion if: (i) their household included at least one child 18 years of age or younger; (ii) they lived in rental accommodations and had lived in their current dwelling for at least one month; (iii) the potential respondent had sufficient fluency in English to complete an oral interview; and (iv) the gross household income was at or below an income threshold based on household size. The thresholds were \$CAN 29999 for a family of two, \$CAN 39999 for a family of three or four, and \$CAN 59999 for a family of five or more ${ }^{(41)}$. These relatively generous thresholds, which are higher than welfare rates in the province of Ontario, were used to ensure that the sample encompassed both the 'working poor' and welfare recipients. In eligible households, the interviewers sought to conduct an in-home structured interview with the person who had primary responsibility for food shopping and management. The interview questionnaire was designed to elicit information on household sociodemographic characteristics, food security status, food shopping habits, use of community food programmes and neighbourhood social capital. Participants gave written consent after being informed about the study objectives and methods. A total of 501 families participated in the study, reflecting a participation rate of $62 \%$. Seventeen families that were initially screened as eligible were found to have incomes that exceeded the eligibility threshold based on the detailed information collected during the interview and were excluded. The analytic sample thus includes 484 families. 
Geographic Information Systems (GIS) software was used to map discount supermarkets in the City of Toronto as a proxy for access to a range of foods at reasonable prices (preliminary analysis indicated that over $80 \%$ of respondents did the majority of their food shopping at discount supermarkets). Data on the location (longitude and latitude) of discount supermarkets were obtained from the University of Toronto Map Library and crosschecked with a list obtained from the City of Toronto and Yellow Pages listings. We also mapped food banks, community gardens and community kitchens using data from programme providers. We focus on these programmes given that they are common community-based responses to food insecurity in Canada.

\section{Measures}

The Household Food Security Survey Module ${ }^{(42)}$ was used to assess food security over the 12 months prior to families' participation in the study. Thresholds adopted by Health Canada were applied to categorize families as food secure or food insecure, indicative of compromises in the quality and/or quantity of food consumed by adults and/or children ${ }^{(1)}$. A variable to distinguish families that were severely food insecure, indicative of reduced food intake and disrupted eating patterns, from more foodsecure families was also created ${ }^{(1)}$.

The distances from each household's dwelling to the nearest discount supermarket, food bank, community kitchen and community garden were calculated using ArcGIS (ESRI, Redlands, CA, USA). Since there is no standard threshold to demarcate adequate geographic food access, we explored associations between household food security and continuous distance variables as well as dichotomous variables based on thresholds of $1 \mathrm{~km}$ and $2 \mathrm{~km}$. Additional measures related to the local area food environment were drawn from the survey and include perceived adequacy of food retail, whether families shopped within their neighbourhood, and transportation costs for a round trip to the supermarket.

To assess perceived neighbourhood social capital, we adopted the scale ${ }^{(43)}$ used in previous food security research ${ }^{(29,30)}$. Respondents were asked whether they agreed (scored as 1) or disagreed (scored as 0) with each of seven statements, the items were summed to give a score ranging from 0 to 7 (two negatively worded items were reverse coded), and a threshold of 3 or lower was applied to indicate low social capital ${ }^{(30)}$.

\section{Statistical metbods}

Multilevel logistic modelling, using the PROC GLIMMIX macro in the SAS statistical software package version $9 \cdot 1 \cdot 3$ (SAS Institute, Cary, NC, USA), was conducted to assess the relevance of household-level variables to food security while accounting for neighbourhood of residence $^{(44)}$. A random intercept null model was used to estimate the proportion of variation in food insecurity and severe food insecurity at the neighbourhood level. We then added fixed effects for household sociodemographic characteristics to assess the extent to which variation in food insecurity across neighbourhoods is attributable to compositional effects. Sociodemographic characteristics included income from all sources over the past 12 months, the household's main source of income, household type, highest level of education obtained by the respondent, immigrant status of the respondent and his/her partner where applicable, the number of adults and number of children in the household, and whether the household lived in market or subsidized rental accommodations to account for the stratification of the sample. (The results of an examination of the associations between these characteristics and severe food insecurity have been published elsewhere ${ }^{(39)}$ and so are only briefly summarized here.)

Models were then run including fixed effects for (i) neighbourhood food access variables and (ii) neighbourhood social capital, to examine the association between these factors and household food security. The models were repeated with household sociodemographic covariates included to account for their potential confounding effect. Because perceptions of neighbourhood cohesion might differ depending on the length of time that a family had lived in the neighbourhood, the social capital model also included a variable indicating the number of years in the current dwelling.

Finally, to shed further light on the relationship between neighbourhood food access and food security, we examined associations between proximity to discount supermarkets, perceived food retail access, cost of transportation for grocery shopping trips and household food security. Consistent with our analytic strategy, both unadjusted models and models including household sociodemographic covariates were run.

\section{Results}

The sample characteristics are outlined in Table 1. Twothirds $(65 \cdot 3 \%)$ of families were food insecure and about a quarter $(27 \cdot 7 \%)$ were characterized as severely food insecure in the 12 months prior to their participation in the study. The prevalence of food insecurity varied across neighbourhoods (Table 2 ) but only $1 \%$ of the variation in food security and less than $1 \%$ of the variation in severe food insecurity was a function of neighbourhood of residence. Lower odds of household food insecurity were observed with increasing income and among families in which the household head and/or his/her partner were a recent immigrant to Canada, while families whose main source of income was welfare had higher odds of food insecurity (Table 1). Similarly, lower odds of severe food insecurity were observed with increasing income, whereas higher odds of severe food insecurity were apparent among households reliant on welfare, those headed by a lone 
Table 1 Household food insecurity in relation to household sociodemographic characteristics among respondents $(n 484)$ from low-income families who had children and who lived in rental accommodations, Toronto, Ontario, Canada, November 2005-January 2007

\begin{tabular}{|c|c|c|c|c|}
\hline & Mean & SD & Adjusted OR of food insecurity* & $95 \% \mathrm{Cl}$ \\
\hline Household income over past 12 months (\$CAN) & 23033 & 8963 & $0 \cdot 97 \|$ & $0.95,0.99$ \\
\hline Number of adults & 1.69 & 0.75 & 0.98 & $0 \cdot 71,1 \cdot 35$ \\
\hline \multirow[t]{2}{*}{ Number of children } & $2 \cdot 07$ & $0 \cdot 75$ & $1 \cdot 20$ & $0.96,1.48$ \\
\hline & $n$ & $\%$ of families & & \\
\hline \multicolumn{5}{|l|}{ Main source of income } \\
\hline Employment & 254 & $52 \cdot 5$ & $1 \cdot 00$ & reference \\
\hline Welfare & 131 & $27 \cdot 1$ & $2 \cdot 52$ & $1 \cdot 44,4 \cdot 43$ \\
\hline Other sourcest & 99 & $20 \cdot 5$ & $1 \cdot 50$ & $0 \cdot 82,2 \cdot 74$ \\
\hline \multicolumn{5}{|l|}{ Household type } \\
\hline Two-parent or lone-fatherł & 224 & $46 \cdot 3$ & $1 \cdot 00$ & reference \\
\hline Lone-mother & 260 & $53 \cdot 7$ & $1 \cdot 08$ & $0 \cdot 64,1 \cdot 82$ \\
\hline \multicolumn{5}{|c|}{ Highest level of education attained by household respondent } \\
\hline Less than high school graduation & 109 & $22 \cdot 5$ & $1 \cdot 02$ & $0 \cdot 60,1 \cdot 72$ \\
\hline Completed high school & 375 & $77 \cdot 5$ & $1 \cdot 00$ & reference \\
\hline \multicolumn{5}{|l|}{ Immigrant status $\S$} \\
\hline Born in Canada & 85 & $17 \cdot 6$ & $1 \cdot 00$ & reference \\
\hline Immigrated $<10$ years ago & 209 & $43 \cdot 2$ & 0.49 & $0.25,0.95$ \\
\hline Immigrated $\geq 10$ years ago & 190 & $39 \cdot 3$ & $0 \cdot 82$ & $0.43,1.55$ \\
\hline \multicolumn{5}{|l|}{ Housing type } \\
\hline Subsidized & 253 & $52 \cdot 3$ & $0 \cdot 77$ & $0 \cdot 49,1 \cdot 23$ \\
\hline Market rental & 231 & $47 \cdot 7$ & $1 \cdot 00$ & reference \\
\hline
\end{tabular}

*Odds ratios were derived from multivariate logistic regression, adjusted for all other variables in the table.

tOther sources of income include Employment Insurance, Worker's Compensation, Child Tax Benefits, seniors' benefits, child support, and rent paid by tenant(s) living in the dwelling.

$\ddagger$ Two-parent families, $n$ 206; lone-father households, $n 18$.

$\S$ Immigrant status is based on the household respondent and/or his/her partner if applicable. In households in which both the respondent and partner were born outside Canada, immigrant status is based on the individual who immigrated most recently.

$\|$ The odds ratio for household income pertains to increments of \$CAN 1000.

mother, and those in which the respondent had less than a high school education ${ }^{(39)}$. There was also a positive association between severe food insecurity and the number of children in the household. After accounting for sociodemographic covariates, the proportion of variation in both food insecurity and severe food insecurity at the neighbourhood level was zero.

The average distance that a household had to travel to reach a discount grocery store was $1.3 \mathrm{~km}$, ranging from $0 \cdot 01$ to $2 \cdot 70 \mathrm{~km}$ across households and from $0 \cdot 25$ to $2.57 \mathrm{~km}$ on average across neighbourhoods. Over fourfifths $(82.9 \%)$ of families lived within $2 \mathrm{~km}$ and $41 \cdot 1 \%$ of families lived within $1 \mathrm{~km}$ of a discount supermarket. In nine neighbourhoods, all families lived within $2 \mathrm{~km}$ of a discount supermarket whereas in one neighbourhood, no family sampled lived within $2 \mathrm{~km}$ of a discount supermarket (Table 2). Over three-quarters of families (78.1\%) agreed that there was adequate access to places to buy food in their neighbourhood and a similar proportion $(75 \cdot 2 \%)$ did the bulk of their food shopping in their neighbourhood; but across neighbourhoods, these proportions ranged from $25 \cdot 5 \%$ to $95 \cdot 2 \%$ (Table 2). A negative curvilinear relationship was apparent between the distance to the nearest discount supermarket and the probability that a family indicated they had adequate access to food retail in their neighbourhood (Fig. 1). For example, while families living $1.5 \mathrm{~km}$ from a discount supermarket had an $80 \%$ probability of reporting their access as adequate, this probability fell to $42 \%$ for families living $2.5 \mathrm{~km}$ from a supermarket. However, there was no association between whether families perceived their food retail access to be adequate and whether they were food insecure $(\mathrm{OR}=0 \cdot 75,95 \% \mathrm{CI}$ $0 \cdot 46,1 \cdot 22$; adjusted OR $(\mathrm{AOR})=0 \cdot 87,95 \% \mathrm{CI} 0 \cdot 53,1 \cdot 41)$ or severely food insecure (OR $=0 \cdot 78,95 \%$ CI $0 \cdot 45,1 \cdot 15$; $\mathrm{AOR}=0 \cdot 77,95 \%$ CI $0 \cdot 47,1 \cdot 29)$.

Of those participants reporting adequate access to food retail, $92 \cdot 6 \%$ lived within $2 \mathrm{~km}$ of a discount supermarket. However, there were no associations between whether families lived within $2 \mathrm{~km}$ of the nearest discount supermarket and whether they were food insecure in either the unadjusted $(\mathrm{OR}=0.93,95 \%$ CI $0.53,1.64)$ or adjusted model, although the effects of income, reliance on welfare and immigrant status on household food security status persisted (Table 3). Similarly, no association with household food insecurity was observed with the use of a continuous distance variable or a threshold of $1 \mathrm{~km}$ (data not shown). There were also no significant associations between geographic access to discount supermarkets and severe food insecurity (data not shown) aside from the marginally significant higher odds of severe food insecurity among families that did not live within $2 \mathrm{~km}$ of a discount supermarket $(\mathrm{OR}=1 \cdot 63,95 \%$ CI $0 \cdot 97,2 \cdot 74)$. This marginal effect did not persist with the inclusion of sociodemographic covariates in the model $(\mathrm{AOR}=1 \cdot 20$, $95 \%$ CI $0 \cdot 69,2 \cdot 09)$. 
Costs for transportation to and from the grocery store were incurred by $61.4 \%$ of families, with the amount of money spent per round trip averaging \$CAN 7.46 (sD \$CAN 6.21). About a quarter of families (26.5\%) drove their own vehicle to the supermarket; the remainder walked or bicycled and reported no cost for transportation. Among those reporting transportation costs, 28.9\% lived within $1 \mathrm{~km}$ and $75 \cdot 8 \%$ lived within $2 \mathrm{~km}$ of a discount supermarket. Approximately half $(57 \cdot 4 \%)$ of those indicating that they had adequate access to food retail in their neighbourhood reported transportation costs to and from the grocery store. There was no relationship between whether families incurred costs for transportation for grocery shopping and whether they were food insecure $(\mathrm{OR}=1 \cdot 32,95 \%$ CI $0 \cdot 88,1 \cdot 97 ; \mathrm{AOR}=1 \cdot 38$, $95 \%$ CI $0 \cdot 90,2 \cdot 11)$ or severely food insecure $(\mathrm{OR}=1 \cdot 18$, $95 \%$ CI $0 \cdot 77,1 \cdot 80 ; \mathrm{AOR}=1 \cdot 34,95 \%$ CI $0 \cdot 84,2 \cdot 15$ ).

The average distances to the nearest food bank, community kitchen and community garden by neighbourhood are outlined in Table 2 . There were no significant associations between whether or not families were food insecure and whether they lived within $2 \mathrm{~km}$ of a food bank $(\mathrm{OR}=0 \cdot 88,95 \%$ CI $0 \cdot 56,1 \cdot 39 ; \mathrm{AOR}=0 \cdot 82,95 \%$ CI 0.55 , $1 \cdot 22)$, community kitchen $(\mathrm{OR}=0 \cdot 77,95 \% \mathrm{CI} 0 \cdot 50,1 \cdot 20$; $\mathrm{AOR}=0.78,95 \% \mathrm{CI} 0.52,1 \cdot 17)$ or community garden $(\mathrm{OR}=1 \cdot 14,95 \%$ CI $0 \cdot 73,1 \cdot 76 ; \mathrm{AOR}=1 \cdot 09,95 \% \mathrm{CI} 0 \cdot 72$, $1 \cdot 65)$. There were also no significant effects on household food insecurity when we used continuous distance variables or thresholds of $1 \mathrm{~km}$, nor for proximity to these programmes and severe food insecurity (data not shown).

The perceived neighbourhood social capital of $44 \cdot 8 \%$ of families was characterized as low, ranging across neighbourhoods from $19 \cdot 5 \%$ to $66 \cdot 7 \%$ (Table 2 ). In the unadjusted model, low social capital was associated with higher odds of household food insecurity ( $\mathrm{OR}=1 \cdot 51,95 \% \mathrm{CI} 1 \cdot 03$, $2 \cdot 22)$; this effect did not persist once sociodemographic variables were included although the effects of income, reliance on welfare and immigrant status on household food security status remained (Table 4). There was no significant association between social capital and household food security status when we predicted severe food insecurity $(\mathrm{OR}=1 \cdot 27,95 \% \mathrm{CI} 0 \cdot 85,1 \cdot 90 ; \mathrm{AOR}=1 \cdot 10,95 \% \mathrm{CI} 0 \cdot 70$, $1 \cdot 73)$.

\section{Discussion}

A very small proportion of the variation in household food security among the families in the current sample was a function of the neighbourhood of residence and this variation was attributable to compositional differences in the sociodemographic characteristics of families. In particular, the significant effects of income, reliance on welfare and immigrant status on food security status persisted through all of our models. The finding of higher odds of food insecurity with declining income is intuitive 


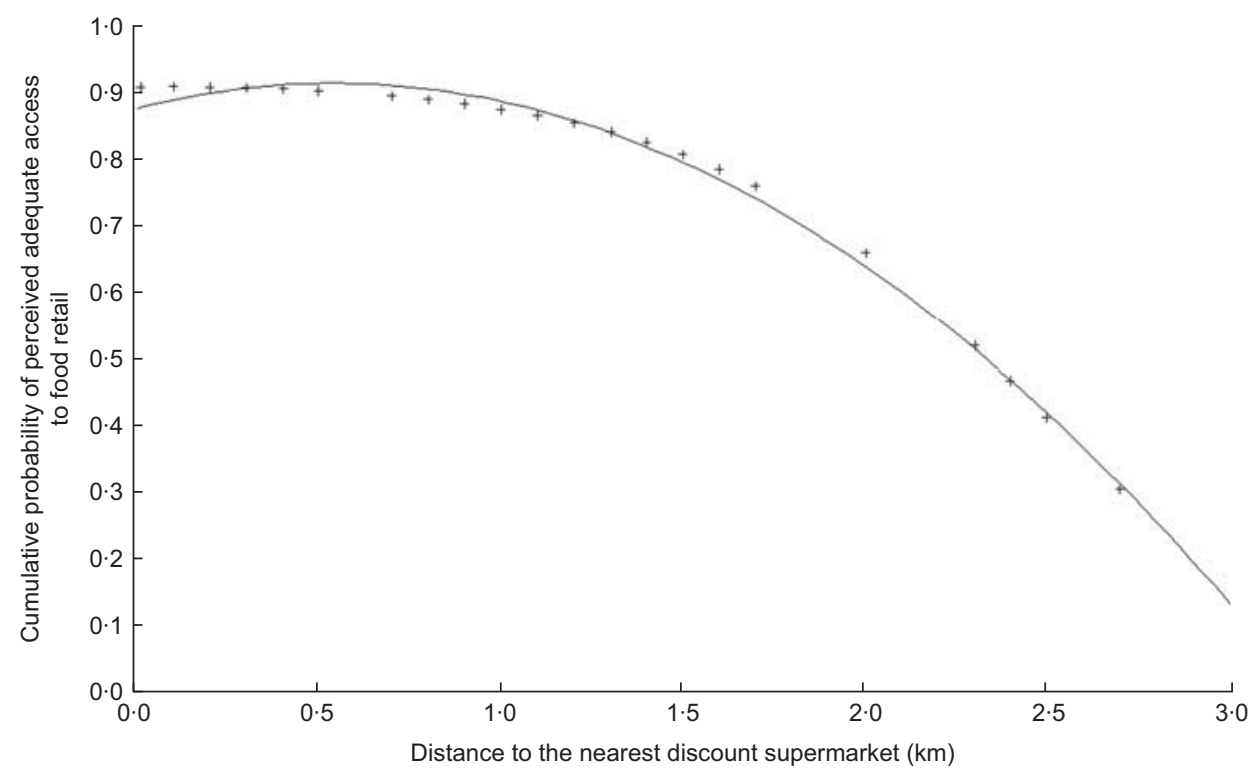

Fig. 1 Cumulative probability plot depicting the relationship between the distance to the nearest discount supermarket (km) and perceived adequacy of food retail access among respondents $(n 484)$ from low-income families who had children and who lived in rental accommodations, Toronto, Ontario, Canada, November 2005-January 2007

Table 3 Household food insecurity in relation to proximity to discount supermarkets among respondents $(n 484)$ from low-income families who had children and who lived in rental accommodations, Toronto, Ontario, Canada, November 2005-January 2007

\begin{tabular}{|c|c|c|}
\hline & Adjusted OR of food insecurity* & $95 \% \mathrm{Cl}$ \\
\hline Do not live within $2 \mathrm{~km}$ of a discount supermarket & 0.73 & $0.43,1 \cdot 26$ \\
\hline Income (in \$CAN 1000 units) & 0.97 & $0.95,1.00$ \\
\hline Number of adults & 0.97 & $0 \cdot 71,1 \cdot 34$ \\
\hline Number of children & $1 \cdot 20$ & $0.97,1.49$ \\
\hline \multicolumn{3}{|l|}{ Main source of income } \\
\hline Employment & $1 \cdot 00$ & reference \\
\hline Welfare & $2 \cdot 52$ & $1 \cdot 44,4 \cdot 43$ \\
\hline Other sourcest & $1 \cdot 49$ & $0 \cdot 81,2 \cdot 73$ \\
\hline \multicolumn{3}{|l|}{ Household type } \\
\hline Two-parent or lone-father & 1.00 & reference \\
\hline Lone-mother & $1 \cdot 11$ & $0.66,1 \cdot 88$ \\
\hline \multicolumn{3}{|c|}{ Highest level of education attained by household respondent } \\
\hline Less than high school graduation & 1.03 & $0 \cdot 61,1 \cdot 74$ \\
\hline Completed high school & $1 \cdot 00$ & reference \\
\hline \multicolumn{3}{|l|}{ Immigrant status $\ddagger$} \\
\hline Born in Canada & 1.00 & reference \\
\hline Immigrated <10 years ago & 0.50 & $0.26,0.97$ \\
\hline Immigrated $\geq 10$ years ago & 0.85 & $0.45,1.61$ \\
\hline \multicolumn{3}{|l|}{ Housing type } \\
\hline Subsidized & $0 \cdot 81$ & $0.50,1 \cdot 29$ \\
\hline Market rental & $1 \cdot 00$ & reference \\
\hline
\end{tabular}

*Adjusted odds ratios were derived from multivariate logistic regression, adjusted for all other variables in the table.

tOther sources of income include Employment Insurance, Worker's Compensation, Child Tax Benefits, seniors' benefits, child support, and rent paid by tenant(s) living in the dwelling.

fImmigrant status is based on the household respondent and/or his/her partner if applicable. In households in which both the respondent and partner were born outside Canada, immigrant status is based on the individual who immigrated most recently.

given that, by definition, food insecurity is related to inadequate financial resources to obtain adequate food. However, the fact that we were able to observe this relationship even in a low-income sample speaks to the potency of this effect. The vulnerability of families reliant on welfare is also not surprising given evidence of the inadequacy of current benefit levels in Ontario ${ }^{(45)}$. The apparent lower vulnerability to food insecurity among recent immigrants compared with those who are Canadian born and immigrants who have been in the country for a longer period of time has also been observed at a national level ${ }^{(6)}$. This finding has not been explored but 
Table 4 Household food insecurity in relation to perceived neighbourhood social capital among respondents ( $n$ 484) from low-income families who had children and who lived in rental accommodations, Toronto, Ontario, Canada, November 2005-January 2007

\begin{tabular}{|c|c|c|}
\hline & Adjusted OR of food insecurity* & $95 \% \mathrm{Cl}$ \\
\hline Low perceived neighbourhood social capital & $1 \cdot 33$ & $0 \cdot 88,2 \cdot 00$ \\
\hline Income (in \$CAN 1000 units) & 0.97 & $0.95,1.00$ \\
\hline Number of adults & $1 \cdot 04$ & $0 \cdot 75,1.45$ \\
\hline Number of children & $1 \cdot 22$ & $0.98,1.51$ \\
\hline \multicolumn{3}{|l|}{ Main source of income } \\
\hline Employment & $1 \cdot 00$ & reference \\
\hline Welfare & $2 \cdot 30$ & $1 \cdot 30,4 \cdot 07$ \\
\hline Other sourcest & $1 \cdot 44$ & $0.78,2 \cdot 65$ \\
\hline \multicolumn{3}{|l|}{ Household type } \\
\hline Two-parent or lone-father & $1 \cdot 00$ & reference \\
\hline Lone-mother & $1 \cdot 18$ & $0 \cdot 69,2 \cdot 00$ \\
\hline \multicolumn{3}{|c|}{ Highest level of education attained by household respondent } \\
\hline Less than high school graduation & $1 \cdot 01$ & $0.59,1.70$ \\
\hline Completed high school & 1.00 & reference \\
\hline \multicolumn{3}{|l|}{ Immigrant status $\ddagger$} \\
\hline Born in Canada & 1.00 & reference \\
\hline Immigrated $<10$ years ago & $0 \cdot 46$ & $0.23,0.93$ \\
\hline Immigrated $\geq 10$ years ago & $0 \cdot 79$ & $0.41,1.51$ \\
\hline \multicolumn{3}{|l|}{ Housing type } \\
\hline Subsidized & $0 \cdot 88$ & $0 \cdot 54,1 \cdot 43$ \\
\hline Market rental & 1.00 & reference \\
\hline Number of years in the current dwelling & 0.97 & $0.93,1.01$ \\
\hline
\end{tabular}

*Adjusted odds ratios were derived from multivariate logistic regression, adjusted for all other variables in the table.

tOther sources of income include Employment Insurance, Worker's Compensation, Child Tax Benefits, seniors' benefits, child support, and rent paid by tenant(s) living in the dwelling.

flmmigrant status is based on the household respondent and/or his/her partner if applicable. In households in which both the respondent and partner were born outside Canada, immigrant status is based on the individual who immigrated most recently.

perhaps relates to the ability of immigrants to draw upon resources from their countries of origin in the short term to buffer themselves against low earnings.

The current study adds to the limited evidence available in Canada on the adequacy of food access in lowincome urban areas and supports recent arguments by Macintyre that the problem of food deserts is contextspecific with no consistent pattern in terms of whether those in poorer communities have poorer access to resources ${ }^{(46)}$. The majority of the families and neighbourhoods in our study appeared to have relatively good food retail access whether measured objectively using GIS or subjectively based on perceptions of adequacy. There was however some variation, with one neighbourhood in particular having poor access. The greater distances that families residing in this neighbourhood must travel to reach amenities must only add to their stress, especially among those struggling with severe food insecurity. Nevertheless, the distances that families had to travel to food retail did not predict household food security status and high rates of food insecurity were observed even in neighbourhoods in which families lived in very close proximity to discount supermarkets. Thus, while good food access is clearly a desirable neighbourhood characteristic, we found no evidence that geographic accessibility mitigates the effects of financial constraints on household food security status. Although we have considered only one type of food retail in characterizing the local area food environment, the bulk of participants reported that they shopped at discount supermarkets, suggesting that this type of outlet is most relevant to their household food access.

Our interrogation of the relevance of physical food access to food security is limited in that we studied a small number of relatively homogeneous neighbourhoods, perhaps limiting our ability to precisely discern the relationship between distance to food outlets and household food security. However, our findings are consistent with those of recent studies from Australia which suggest that only a small proportion of variation in food purchasing and consumption is at the level of the neighbourhood $^{(23,25,47)}$. Similarly, other research has shown that features (either objectively measured or perceived) of the food shopping environment did not explain socioeconomic inequalities in fruit and vegetable consumption among a sample of Dutch adults ${ }^{(24)}$ and that the local density of fruit and vegetable stores did not explain education-related variations in fruit and vegetable intakes among a sample of Australian women ${ }^{(25)}$.

It has been argued that transportation costs can impinge upon the cash available for food ${ }^{(10,48-50)}$ and that local food access within walking distance is particularly important for those living in low-income areas ${ }^{(15)}$. Our results suggest that the demands associated with grocery shopping for poor families are more complex. Despite the apparent adequacy of food retail access in most neighbourhoods, over half of the families in the present study incurred transportation costs, presumably because it was too difficult for them to carry their groceries home on foot. The proximity of retail access likely afforded them some 
advantage, given that taxi costs are a function of distance. Perhaps the modest transportation costs incurred account for our inability to discern an association between proximity to discount supermarkets and household food security status. It is also conceivable that our analysis is confounded by differences in the frequency with which families shopped for groceries during the course of a month - something not assessed in our study. Our results add to the literature $^{(15)}$ highlighting the need to consider both distance and means of transportation when assessing the adequacy of food retail access for low-income families. However, there is also a need for more research to elucidate other factors that may shape low-income households' shopping behaviours.

The close proximity of most families to food banks, community kitchens and community gardens must reflect the deliberate efforts of community agencies to locate these resources in low-income neighbourhoods. The lack of relationship between programme access and household food insecurity can perhaps be explained by the low levels of programme utilization in this sample ${ }^{(39)}$ and the limited nature of the supports available from these programmes ${ }^{(27,51,52)}$. These findings provide further evidence of the need for responses to food insecurity that go beyond community-level supports.

Among the families in our sample, low perceived social capital was associated with higher odds of household food insecurity, similar to Walker et al.'s findings of an inverse relationship between social capital and household food insecurity among a sample of low-income Ohio women $^{(29)}$. However, Walker et al.'s analysis did not account for the potential confounding effect of household characteristics whereas in our study, the loss of the effect of social capital on food insecurity once we included sociodemographic covariates suggests that the observed association is attributable to household-level characteristics. We also observed no effect of perceived neighbourhood social capital on the odds of severe food insecurity, in contrast to the findings of Martin et al. who found that social capital was inversely associated with the odds of hunger (a measure of severe food insecurity) among a sample of low-income households in Hartford, Connecticut, even after accounting for socio-economic status. Based on their findings, those authors suggested that interventions that foster the development of social capital might also foster food security ${ }^{(30)}$. Our findings provide no support for this argument, but the discrepancy highlights the need for more research on this topic. Pearce and Davey Smith have argued that because social capital, like income inequality and health, is impacted by macro-level social and economic policies, strategies that aim to increase the social capital of communities without also considering the social context may be akin to 'blaming the victim' at a community level and thus may be ineffective or even damaging ${ }^{(38)}$. A fuller understanding of the relevance of neighbourhood social capital to household food security is thus needed before interventions to improve social capital as a means of ameliorating income-related food access problems are warranted.

In summary, the findings of the present study raise questions about the notion that food insecurity is a function of the characteristics of the neighbourhoods in which families live, suggesting that working at a neighbourhood level to improve local area food access or social cohesion may not be an effective strategy for the amelioration of problems of food insecurity that are rooted in inadequate financial resources. Our findings do however support calls for policy change to address the factors that constrain food purchasing among low-income families $^{(27,53)}$.

\section{Acknowledgements}

This study was supported by the Canadian Institutes for Health Research (IGP-74207, MOP-77766). S.I.K. was a doctoral student at the University of Toronto at the time that this study was conducted and received financial support from an Ontario Graduate Scholarship and a Social Sciences and Humanities Research Council of Canada Doctoral Scholarship. Neither author has any conflicts of interest to declare. Both authors conceived of the study and oversaw data collection. S.I.K. conducted the analyses and drafted the manuscript. V.T. made substantive contributions to the analytic framework, interpretation of the findings and revision of the manuscript. We are grateful to Richard Maaranen (Centre for Urban and Community Studies, University of Toronto) for his GIS work on this study. We also gratefully acknowledge our collaborators at the City of Toronto Shelter, Housing and Support Division and Toronto Public Health.

\section{References}

1. Office of Nutrition Policy and Promotion (2007) IncomeRelated Household Food Security in Canada. Report no. H164-42/2007E. Ottawa, ON: Health Canada.

2. Nord M, Andrews M \& Carlson S (2008) Household Food Security in the United States, 2007. Economic Research Report no. ERR-66. Washington, DC: Economic Research Service, US Department of Agriculture.

3. Parnell WR, Reid J, Wilson NC et al. (2001) Food security: is New Zealand a land of plenty? $N Z$ Med $J \mathbf{1 1 4}$, $141-145$.

4. Booth S \& Smith A (2001) Food security and poverty in Australia - challenges for dietitians. Aust J Nutr Diet 58, $150-156$

5. Holmes B (2008) The influence of food security and other social and environmental factors on diet in the National Low Income Diet and Nutrition Survey. Proc Nutr Soc 67, E88.

6. Che J \& Chen J (2001) Food insecurity in Canadian households. Health Rep 12, issue 4, 11-22.

7. Vozoris N \& Tarasuk V (2003) Household food insufficiency is associated with poorer health. J Nutr 133, 120-126. 
8. Ledrou I \& Gervais J (2004) Food insecurity. Health Rep 16, issue $3,47-51$.

9. Lang $\mathrm{T} \&$ Caraher M (1998) Food poverty and shopping deserts: what are the implications for health promotion policy and practice? Health Educ J 58, 202-211.

10. Furey S, Strugnell C \& McIIveen H (2001) An investigation of the potential existence of 'food deserts' in rural and urban areas of Northern Ireland. Agric Hum Values 18, 447-457.

11. Wrigley N (2002) 'Food deserts' in British cities: policy context and research priorities. Urban Stud 39, 2029-2040.

12. Larson NI, Story MT \& Nelson MC (2009) Neighborhood environments: disparities in access to healthy foods in the US. Am J Prev Med 36, 74-81.

13. Cummins S \& Macintyre S (1999) The location of food stores in urban areas: a case study in Glasgow. $\mathrm{Br}$ Food $\mathrm{J}$ 101, 545-553.

14. Apparicio P, Cloutier M-S \& Shearmur R (2007) The case of Montréal's missing food deserts: evaluation of accessibility to food supermarkets. Int J Health Geogr 6, 4.

15. Larsen K \& Gilliland J (2008) Mapping the evolution of 'food deserts' in a Canadian city: supermarket accessibility in London, Ontario, 1961-2005. Int J Health Geogr 7, 16 .

16. Pouliot N \& Hamelin AM (2009) Disparities in fruit and vegetable supply: a potential health concern in the greater Québec City area. Public Health Nutr 12, 2051-2059.

17. Bertrand L, Thérien F \& Cloutier M-S (2008) Measuring and mapping disparities in access to fresh fruits and vegetables in Montréal. Can J Public Health 99, 6-10.

18. Smoyer-Tomic KE, Spence JC \& Amrhein C (2006) Food deserts in the Prairies? Supermarket accessibility and neighborhood need in Edmonton, Canada. Prof Geogr 58, 307-326.

19. Morland K, Wing S \& Diez-Roux A (2002) The contextual effect of the local food environment on residents' diets: the Atherosclerosis Risk in Communities study. Am J Public Health 92, 1761-1767.

20. Rose D \& Richards R (2004) Food store access and household fruit and vegetable use among participants in the US Food Stamp Program. Public Health Nutr 7, 1081-1088.

21. Bodor J, Rose D, Farley T et al. (2008) Neighbourhood fruit and vegetable availability and consumption: the role of small food stores in an urban environment. Public Health Nutr 11, 413-420.

22. Inglis V, Ball K \& Crawford D (2008) Socioeconomic variations in women's diets: what is the role of perceptions of the local food environment? J Epidemiol Community Health 62, 191-197.

23. Turrell G, Blakely T, Patterson C et al. (2004) A multilevel analysis of socioeconomic (small area) differences in household food purchasing behaviour. J Epidemiol Community Health 58, 208-215.

24. Giskes K, van Lenthe FJ, Kamphuis CBM et al. (2008) Household and food shopping environments: do they play a role in socioeconomic inequalities in fruit and vegetable consumption? A multilevel study among Dutch adults. J Epidemiol Community Health 63, 113-120.

25. Ball K, Crawford D \& Mishra G (2008) Socio-economic inequalities in women's fruit and vegetable intakes: a multilevel study of individual, social and environmental mediators. Public Health Nutr 9, 623-630.

26. Tarasuk V (2005) Household food insecurity in Canada. Top Clin Nutr 20, 299-312.

27. Dietitians of Canada (2005) Individual and household food insecurity in Canada: Position of Dietitians of Canada. Can $J$ Diet Pract Res 66, 43-46.
28. Kalina L (2001) Building Food Security in Canada: A Community Guide for Action on Hunger. Kamloops, BC: Kamloops FoodShare.

29. Walker JL, Holben DH, Kropf ML et al. (2007) Household food insecurity is inversely associated with social capital and health in females from Special Supplemental Nutrition Program for Women, Infants, and Children households in Appalachian Ohio. J Am Diet Assoc 107, 1989-1993.

30. Martin KS, Rogers BL, Cook JT et al. (2004) Social capital is associated with decreased risk of hunger. Soc Sci Med 58, $2645-2654$.

31. Hamelin AM, Habicht JP \& Beaudry M (1999) Food insecurity: consequences for the household and broader social implications. J Nutr 129, 2 Suppl., 525S-528S.

32. Hamelin AM, Beaudry M \& Habicht J-P (2002) Characterization of household food insecurity in Quebec: food and feelings. Soc Sci Med 54, 119-132.

33. Tarasuk VS (2001) Household food insecurity with hunger is associated with women's food intakes, health, and household circumstances. J Nutr 131, 2670-2676.

34. Kawachi I, Kennedy BP, Lochner K et al. (1997) Social capital, income inequality, and mortality. Am J Public Health 87, 1491-1498.

35. Fujiwara T \& Kawachi I (2008) Social capital and health. A study of adult twins in the US. Am J Prev Med 35, 139-144.

36. Ziersch AM, Baum FE, Macdougall C et al. (2005) Neighbourhood life and social capital: the implications for health. Soc Sci Med 60, 71-86.

37. Chavez R, Kemp L \& Harris E (2004) The social capital:health relationship in two disadvantaged neighbourhoods. J Health Serv Res Policy 9, Suppl., 2, 29-34.

38. Pearce N \& Davey Smith G (2003) Is social capital the key to inequalities in health? Am J Public Health 93, 122-129.

39. Kirkpatrick SI \& Tarasuk V (2009) Food insecurity and participation in community food programs among low-income Toronto families. Can J Public Health 100, 135-139.

40. United Way of Greater Toronto, Canadian Council on Social Development (2004) Poverty by Postal Code: The Geography of Neighbourhood Poverty 1981-2001. Toronto, ON: United Way of Greater Toronto.

41. Statistics Canada (2003) CCHS Cycle 1.1 (2000-2001), Public Use Microdata File Documentation. Ottawa, ON: Statistics Canada.

42. Bickel G, Nord M, Price C et al. (2000) Guide to Measuring Household Food Security. Alexandria, VA: US Department of Agriculture, Food and Nutrition Service, Office of Analysis, Nutrition and Evaluation.

43. Sampson RJ, Raudenbush SW \& Earls F (1997) Neighborhoods and violent crime: a multilevel study of collective efficacy. Science 277, 918-924.

44. Raudenbush SW \& Bryk AS (2002) Hierarchical Linear Models, 2nd ed. Thousand Oaks, CA: Sage Publications.

45. National Council of Welfare (2008) Welfare Incomes, 2006 and 2007. Report no. 128. Ottawa, ON: National Council of Welfare.

46. Macintyre S (2007) Deprivation amplification revisited; or, is it always true that poorer places have poorer access to resources for healthy diets and physical activity? Int J Behav Nutr Phys Act 4, 32.

47. Pearce J, Hiscock R, Blakely T et al. (2008) The contextual effects of neighbourhood access to supermarkets and convenience stores on individual fruit and vegetable consumption. J Epidemiol Community Health 62, 198-201.

48. Hitchman C, Christie I, Harrison M et al. (2002) Inconvenience Food. London: Demos.

49. Travers KD (1996) The social organization of nutritional inequities. Soc Sci Med 43, 543-553. 
50. $\mathrm{NCH}$ (2004) Going Hungry: The Struggle to Eat Healthily on a Low Income. London: $\mathrm{NCH}$.

51. Irwin J, Ng V, Rush $\mathrm{T}$ et al. (2007) Can food banks sustain nutrient requirements? A case study in Southwestern Ontario. Can J Public Health 98, 17-20.

52. Hamelin AM, Mercier C \& Bedard A (2008) Perceptions of needs and responses in food security: divergence between households and stakeholders. Public Health Nutr 11 1389-1396.

53. Chronic Disease Prevention Alliance of Canada (2007) CDPAC Policy Position: Food Security in Canada - A Leadership Opportunity Towards Health Promotion and Reduction in Chronic Disease. Ottawa, ON: Chronic Disease Prevention Alliance of Canada. 